\title{
Translation Strategies and Its Implications for Cultural Transference
}

\author{
Yameng Zhang \\ Zhejiang Yuexiu University, Shaoxing, China \\ Email: 229146776@qq.com
}

How to cite this paper: Zhang, Y.M. (2021) Translation Strategies and Its Implications for Cultural Transference. Open Access Library Journal, 8: e7469.

https://doi.org/10.4236/oalib.1107469

Received: April 28, 2021

Accepted: May 24, 2021

Published: May 27, 2021

Copyright ( $) 2021$ by author(s) and Open Access Library Inc.

This work is licensed under the Creative Commons Attribution International License (CC BY 4.0).

http://creativecommons.org/licenses/by/4.0/

\begin{abstract}
Previous studies have shown how the translation of Chinese texts into English holds certain problems. With this research, the aim is to understand whether best practices can be found, taking into consideration different types of translation strategies. In order to find an answer, different translation techniques and literature on this topic are discussed. When translating, it is of great importance to keep in mind what the English reader appreciates and values. In order to understand which techniques should be used, the perspective of the reception theory is employed within this research. Moreover, cultural sensitivity is extremely important in the reception of Chinese texts for English readers. In order to conduct an evaluation, the different techniques are consulted by researching well-known and well-received translations. The four strategies used to do this are foreignization, annotation, reader-oriented strategy and radical alteration. These analyses of translations result in several implications for the use of translation techniques. Cultural sensitivity can be applied especially by use of annotation, the reader-oriented strategy or a combination of the two. These two strategies can most effectively contextualize the text for the reader, retain a pleasurable reading experience and transfer Chinese culturally loaded words into English.
\end{abstract}

\section{Subject Areas}

Applied Linguistics

\section{Keywords}

Chinese Literature, Penguin Classics, Translation Strategies, Culturally

Loaded Words, Best Practices

\section{Introduction}

In the past decades, the translation of Chinese literature has developed and ad- 
vanced; currently magazines and journals devoted to contemporary Chinese literature are proliferating. Before 1949, China-related English publications were predominantly classic works of religion and philosophy. Occasionally modern voices appeared such as Lao She's Rickshaw Boy and the prolific publications of Lin Yutang. Scholars devoted themselves to contemporary literature and produced translations in national and increasingly in international literary magazines. The number of translators of Chinese texts to English is increasing. This is necessary in order to make Chinese texts available to English readers for purposes of cultural exchange and to share the richness of Chinese literature and essays. Problems arise in the transfer of Chinese texts into the world through literature and poetry. These translation problems are a bottleneck in the cultural exchange between China and foreign countries and therefore should be tackled and researched.

Translation cannot be understood as merely changing one language into another one. It is a complicated process of dealing with nuances between text, subtext and context. Translation is sometimes understood as a practical task of seeking and detecting equivalents in other languages. However, a good translator knows that translating is not just managing the denotative but also the connotative meanings. These structures of indications engage with culture, politics and aesthetics, which will interact when messages or meanings are placed beyond languages. Translation is a creative process as well as a practical assignment. Psychological truths move from one place to the other and change into new ways of linguistic expressions. The way those processes can come to light, changed or maintained is the hardest challenge for a translator.

Complexities of translation are tangled with social and cultural changes that have taken place in the past years and we refer to it also as "globalization". New interconnectivities in cultural and social developments caused new imaginaries affecting people's perception of the world and reception of translated texts. These nuances conveyed from the original to the translated text can thus be considered global-local interactions. One of the problems is that background assumptions of Chinese readership of texts differ astonishingly from the English readership. Chinese readers aesthetically assume that texts should be ambiguous and implicit in meaning or content, leaving space for artistic interpretation. Chinese texts should be freely structured since it is supposed to result in mental relaxation for readers. Such aesthetic implications do not always coincide with expectations and habits of English readers. This makes the translation, if taken too literally, difficult to be understood and appreciated. By reading this paper, the aim is to understand which techniques can overcome linguistic problems of word choice, meanings and transference of culturally loaded words and sayings.

Section 3 discusses translation issues of Chinese to English in general. Section 4 discusses translation techniques which are well-received and is chosen to understand whether earlier works of translation were different from the later techniques which were well-received. Thereafter, the techniques used for canonization into the Penguin Classics (Section 5) are outlined since we want to know 
which techniques are well-received. Section 6 is about the reception theory to stress and incorporate the view of the reader. Then confirmations are listed on the fact that often the combination of literal translation with free translation and annotation is received as comfortable reading experiences close to the culture of origin.

\section{Methodology}

This exploration of translation styles of Chinese to English texts should result in the evaluation of different techniques which can be applied in translating Chinese to English texts. The reason for doing so is to evaluate whether best practices of translation strategies can be established. This might have implications for the act of translating Chinese texts into English texts and can be used in education or by translators. In order to conduct this research, translation techniques which are perceived as legitimate and are accepted by English readers are sought. Therefore, techniques used in the canonization of Chinese literary works are used. The translation techniques of Chinese literature taken up by Penguin Classics are outlined in this paper. Moreover, it is of importance to understand the difficulties of translating Chinese to English. Literature about this issue is consulted to reach that goal.

Thereafter, research on the acceptance of translation techniques is considered to achieve an analysis of the techniques and to understand the reception and acceptance by English readers. This is conducted by looking up different researches conducted on this topic. Finally, the different levels of acceptance are compared in the discussion to find out which techniques can be considered as best practices.

\section{Chinese to English Translation and Its Difficulties}

Several authors have outlined difficulties in the translation of Chinese modern essays due to the differences of writing style and cultural background between Chinese and English languages. For instance, Xie Tianzhen [1] researched and concluded how cultural awareness can be a bottleneck in translation as well as the solution to improve translations. Moreover, Richa $\mathrm{Hu}$ [2] has discussed problems of Chinese to English translations and vice versa. Translation is essential in aiding Chinese literary works to enter the world. However, the hinderance can be ascribed to translation. Translation problems are highly complex, in terms of language, culture and tradition and have been a problem already for many years.

The problems go two ways. On the one hand the obstacles of understanding Chinese for foreign translators and the obstacles of expressing themselves in English for the Chinese translators. Profound Chinese words are seemingly simple, but it is difficult to grasp their cultural implications. Names, places and other culture loaded words in Chinese often hold a rich meaning. For instance, the English translation of Luoto Xiangzi in English book Rickshaw boy. Evan King, 
the translator of Rickshaw Boy chose to translate the names, proverbs, places and dialects literally. The first to question this manner of translating names was Lao She in 1948. He wrote in the letter "to Lloyd" that in Chinese the "Xiang" in the name of "Xiangzi" can be interpreted as "faithfulness", "good luck" or "success". "Happy Boy" which was supposed to be the equivalent in English obviously does not cover the load.

Chinese translators face the same problems as foreign translators and find difficulty in translating certain culture loaded words. When Wang Jizhen translated Tuanmu Kangliang's "Beyond Willow Wal", he transliterated the character Shi Tou into "Shih Tou". Er Huzi into "Erh Hu-tzu", Gao Liang into "Gaoliang", Die Die into "dieh dieh" [3]. These two examples are extremes of English translation of culture-loaded words and can be considered as obstructions in achieving cultural acceptance of Chinese literature in the English-speaking world. Tackling translation issues of Chinese texts into English are therefore highly important so that the richness of Chinese literature and essays can be shared. The problems previously stated is why this research delved into this topic of translation strategies.

\section{Earlier Well-Received Translation Techniques}

Lin Yutang (1895-1976) is a well-known Chinese writer and translator in the West and in China. He published an English translation of a Chinese story entitled "A Nun of Taishan". The story was published in A Nun of Taishan and Other Translations. It revolves around Yiyun, a young nun at a convent on Mount Tai in the late 19th century, as the main character. Yiyun, in her failure in the search for love, finds meaning and peace through Daoism, Confucianism and Buddhism. This makes her change into a happy woman and a religious educator. The revision was performed in 1951 by Lin and he included it in $\mathrm{Wi}$ dow, Nun and Courtesan in which he chose to collect special tales about Chinese women.

The original story was written by Liu E, a brilliant writer and thinker of the late Qing Dynasty. "A Nun of Taishan" is part of the first six chapters of the second part of Liu E's semi-autobiographical novel The Travel of Laocan. Lin managed to get a copy of the chapters from one of Liu E's relatives and demanded them to publish it in the magazine The Human World that Lin had constructed. Thereafter, another edition was published in 1935 with a preface by Lin by Lianglou Publishers. After that publication, Lin started on the translation to make the story available to English readers in China. The writer of the story, Liu E, was praised for expressing his ideas on several subjects, as for instance religious ideals of Tai-ku. He blends these ideas into the stories of main characters and they find salvation in religion and religious ideas in their lifetimes.

The intention of the translator Lin is to demystify Chinese religion and present a positive image of Chinese women. In the introduction to Widow, Nun and Courtesan Lin emphasizes that Yiyun's story is not only one of the best 
Chinese novels, it represents a sophisticated and human perspective on religion. This reveals Lin's strong will to use the story to present an accurate picture of Chinese religion to his Western readers. Lin was a modern thinker and translator and understood the significance of employing a Chinese viewpoint to interpret China's cultural essence. In 1917, he pointed out that the task for foreigners to observe a country might be too great of a task if one wants appreciation of the native ideals and aspirations. Lin's goal was to change misrepresentations and stereotypes about China. He aimed to provide a more accurate and positive picture of China. Lin published translations in English by interpreting Chinese life and cultural essence. For instance, My Country and My People (1935) and The Importance of Living (1937). He also translated several Chinese classics, such as The Wisdom of Confucius (1938) and Chuang Tzu (1957) [4].

As Lin commented, Yiyun's story was one of the best Chinese novels. The image of Yiyun is well focused, and the atmosphere is delicately elaborated. While translating the story into English, Lin did not need to make dramatic changes. Instead, he did make minor changes and adaptations to refine the image of Yiyun and provide a better cross-cultural understanding for readers. Minor changes in the whole narrative structure were made to create a novel close to the Western genre. Lin eliminated characteristics of Chinese traditional fiction, such as the formula of beginning with "It is told" and having each chapter end in suspense. Furthermore, he did not add a two-line poetic summary of the content as titles of the chapter. He also deleted half of the content of the first chapter in order to create a detailed image of Yiyun and launched her story more quickly than the original. Lin shows cross-cultural understanding when he describes the process of Yiyun's awakening from her dreams. Parts of her dreams make sense for people who know Chinese customs but could be odd for English readers. These parts are removed in the translation to avoid misunderstanding of the character.

An important strategy, employed by Lin, is the use of an analogue in the target culture. This facilitates cross-cultural understanding of this story. Lin found corresponding Western figures for the Chinese ones. For instance, the term "Pluto's temple" is used as an equivalent to the Yenlomiao in Chinese. Analogues are found in Western culture to create a nuanced image of Yiyun.

As Fang Lu reflects, Lin's translation strengthens the original texts and retains vitality. Lin intended not only to demystify Chinese religion, but also to present to the West a positive image of Chinese women. The story was successfully presented and made available to English readers and resulted in a more humanistic version of Chinese religion for Western audiences. Because of this translation, religion was personified and hereby Lin impacted the view of Chinese religion and women to the outside world. Thus, it shows that drastic rewritings do not necessarily result in good translations. Small nuances and free translations to keep the main message are hereby shown to be of quality, however, a level of cultural understanding is necessary to be able to do this. The following sections will delve into other techniques of translations. 


\section{Strategies in Penguin Classic's Translations of Chinese Literary Work}

Publishing of literary works is an important step in the recognition of it. Publishers can be understood as institutions outside the literary system that can promote or hinder the acceptance of these works, its reading and rewriting of these works. Especially recognized publishers play an important role in this acceptance. This research takes into consideration strategies used by a well-known publisher namely the Penguin publisher. Penguin Classics is the leading publisher of classic literature in the English-speaking world and is a major power in education. The series holds over 1300 titles and progressively includes an increasing number of non-fiction and non-Western literature in translation. For English readers, the Penguin classics shape much of the awareness of non-English literature because of its "excellent selection and sound translations of ancient and modern world literature" [5]. The problem might be that the Penguin classics are chosen to fit Western ideas and therefore do not represent the full depth and wide collection of Chinese literature. It is still of importance to look at the translation techniques used for the Chinese works to be published in the Penguin classics since we can learn lessons from the techniques which are recognized and read by English readers. The different techniques used for the Penguin Classics can be identified as follows.

\subsection{Foreignization}

One of the strategies is to highlight the foreign elements in translations by attaching importance to the allegiance and authority of its translations. The translator can choose to register the linguistic and cultural differences. In dealing with culture-specific Chinese expressions, they have used literal translation and stayed close to the original text using explication, transliteration or compensation. This creates a "foreign" experience for the reader. This can also be referred to as defamiliarizing effects and prevent immediate understanding which creates new perceptions to the reader's mind. Foreignness in translation is hereby regarded as a form of originality and this type of translating style results in unfamiliar translations and challenges the reader with unexpected imagery and unfamiliar grammatical or lexical choices.

For example, the translator of Love in a Fallen City translated expressions meaning "to abuse someone by pointing at someone else" to "pointing at the mulberry but cursing the locust tree". Another example is "bleeding from one's mouth, nose, and ears" translated into "spouting blood from all seven bodily openings". By doing so the translator aimed to retain the Chinese work's rich verbal texture by maintaining literary tools as paradoxes, literary allusions and wordplay.

\subsection{Scholarly Annotation}

A second translation strategy can be referred to as scholarly annotation meaning 
that the aim of the translation is to create a more informed intellectual or cultural context for the text. The translator can edit, annotate, comment, gloss and provide own references to create in order to do so. It creates extra volume to the explanatory material and intends to preserve the complexity and profundity of the original text. This will present a rich and diverse cultural identity in order to arouse a certain respect for the Chinese text in the English reader. The use of paratextual material like prefaces, introductions and afterwords has special pragmatic status; the result of the use of this tactic is that the text is read in the desired way. By adding introductions and afterwards of the translators themselves and of well-known scholars of Chinese literature the legitimacy and contextualization of the text will be increased.

N. K. Mao, for instance, gives in the extended afterword for Fortress Besieged, a comprehensive overview of Western criticism of the novel. This is followed by an analysis of the artistic features of the book. By this means he praises the novel as "China's greatest novel" and the author as "China's foremost scholar novelist".

\subsection{Reader-Oriented Strategy}

As certain translators choose the technique of foreignization, another method is to adopt a reader-oriented strategy. This strategy bears a recontextualization of the translation in order to give into the assumed needs of the audience. By this means idiomatic and readable texts in English are prioritized. Julia Lovell used in her translation of The Complete Fiction of Lu Xun that to intensify the fluency of the text she used a bare minimum of footnotes and endnotes. Chinese background information is integrated in the texts in a discrete, wary and economical way. This offers a more faithful version of the original reading experience than a version that is translated very literal.

The translator of The Complete Fiction of Luxun replaced Chinese culture-specific sentences in the novel with simple and local and informal English expressions exhibiting as "a valuable Ming incense-burner and as a miscellany of calligraphic styles". Another much discussed and cited example is the translation by Hawkes of The Story of the Stone, in this translation many Chinese culture-bound expressions are assimilated to Western norms: go to Mount Wutai is translated as "go to heaven" which generated a fluent and pleasurable version which has received international recognition implying that this form is perceived by general readers as a pleasurable manner to read.

A strategy that goes a step further is radical alterations made to the work's structure in order to conform the work to the psychology and reading habits of an English readership. In Arthur Waley's translation of Monkey, the translator even altered the title to Journey to the West in order to adhere to English readers and their Western inclination to read about individual and personal journeys. The translator omitted seventy chapters of the Chinese novel and removed even descriptive chapters and shifted the perspective of the book from the quartet's 
pilgrimage to the development of the monkey king, a single character since it is a Western tradition to shift the focus to personal growth and development.

The latter strategy is thus perceived as a read that engages their readers emotionally and intellectually. However, the pitfall, of losing culture loaded meaning of the texts, lurks in this strategy as previously discussed to be one of the problems of translating Chinese literature into English.

\section{Reception Theory}

In this paper the reception theory is used to understand the relation between the translation strategies discussed and the literature that is received by the readers. The research of reception is an acknowledged and established field of research and methodology in comparative literature. However, only in the last thirty years academics started to see the relevance and deeper implications; within this field translation is often investigated as a cultural and linguistic mediator since it plays an important role in transferring culture and ideology. Culture has always been a main issue of translation since it is integrated in the text and is only perceptible when put in context. The denotative meaning hereby should also instigate the connotative meaning. In other words, translation is the bridge or the barrier between the source culture and the target culture. Reception is not merely when a translated text is popular however refers to the response or the interpretation of the reader considering the message, aesthetic elements and form [4]. By using the reception theory as a perspective of this paper, the relation between literary texts and readers is at the centre of attention. Reception theory supports the shift of focus from target text to the reception of target readers. This reminds translators to attach importance to right strategies in order to please the reader.

\subsection{Zhang Peiji's Translation of "Xiang"}

As Zheng (2016) has written in translation of Chinese essays, the cognition of English readers and the difference between Chinese writers is stated to be important. He analyses the translation of Chinese essay "Xiang" ("The Lane") and is analysed from perspectives of rhythm, style and spirit. Zheng also stresses the importance of the cognitive context of the reader and the lack of knowledge of the Chinese words. The famous Chinese essay translator Zhang Peiji produced a translation that is understandable and appreciated by English readers. This professor and translator is one of the most famous English translators in China and is especially known for his translation series of Selected Modern Chinese Essays.

Zhe Zhong Xiang, Chang Zai Jiang Nan De Xiao Cheng Shi Zhong, You Ru Gu Dai De Shao Nv, Duo Zai Pi Jing De Shen Gui, Qing Yi Bu Ken Pao Tou Lu Mian.

The translation is as follows: "Often tucked away in a small town south of the Yangtse River, the lane, like a maiden of ancient times hidden away in a secluded boudoir, is reluctant to make its appearance in public" [6].

He uses the tactic of paraphrasing or in other words the "reader-oriented 
strategy". Zheng argues that a loss of meaning is sometimes necessary in order to achieve a pleasurable reading experience for the foreign reader since they do not have background information and assumptions with a culturally loaded word.

Ta Ke Neng Shi Yi Tiao Xian Dai De Wu Yi Xiang

"It may be a modern version of Wu Yi Xiang, a special residential area of nobility in the Jin Dynasty southeast of today's Nanjing" [6].

Another way is to transliterate and explain certain words as the above citations illustrate. This is an effective way of translation but is very specifically applicable for certain words. The elaborate explanation adequately translates it to fit the understanding of the English reader.

In all the translations of the well-known writer a certain form of adapting to the foreign reader. The next translation supports this argument where this word "Hong Chen" has been converted into an English expression "hustle and bustle" and thus an English expression is used.

Ge Jue Le Shi Chan De Hong Chen

"Cut off from the hustle and bustle of busy cities" [6].

In this example, which technique can supply some value of English culture to the loss of the cultural meaning specific to Chinese language.

The word "Hong Chen" frequently used in ancient Chinese times, such as "Yi Ji Hong Chen Fei Zi Xiao, Wu Ren Zhi Shi Li Zhi Lai” the literal translation is "red dust", however, the readers who does not have related background information will not be able to understand this, therefore using English expression might be preferred for instance. This shows how context is pivotal for the reader's understanding.

According to this research the combination of literal translation with free translation and the combination of literal with annotation are considered as best practices since these do a better job in translating cultural images according to the principles of reception theory.

\subsection{Comparison of Four Translations of "Chang Hen Ge"}

The differences between four English translations of "Chang Hen Ge" by Chinese poet Bai Juyi in the Tang dynasty can tell us more about how translations are received by the audience. Even though this analysis refers to poetry, it can be used in this research because the aim is to understand best practices of culturally loaded words, clauses and texts. Poetry, as literature, aims to pleasure and teach the reader by means of language and culture and contains culturally loaded words.

Yang (2019) compared the four translations by William John Bainbrigge Fletcher, Herbert Allen Giles, Xu Yuanchong and Yang Hsien-yi and Gladys Yang. Yang concludes that Xu Yuanchong does a good job in translating cultural images in "Chang Hen Ge" [7] according to perspective of reception theory. The reason for this is that $\mathrm{Xu}$ tries to retain the cultural images and aesthetic beauty of poetry of the original poem by combining literal translation with annotation 
and combining literal translation with free translation [7] and reveals charms of Chinese culture.

\subsection{Combining Literal Translation with Annotation}

Literal translation can be understood as the alteration of text from one language into another, with or without transferring the sense of the source text [8]. If the original meanings can be conveyed easily and accurately this technique of literally translating would be preferred. As repeatedly discussed, yet, due to linguistic and cultural differences of cultural images, word-to-word translation often does not transfer original senses. The combination of literal translation with (scholarly) annotation may maintain the original imagery and therefore expands English readers' assumptions and spreads Chinese traditional culture.

Original: Han Huang Zhong Se Si Qing Guo

Fletcher: The Lord of Han loved beauty

In love's desire he pined.

Giles: His Imperial Majesty, a slave to beauty,

longed for a "subverter of empires";

The Yangs: Appreciating feminine charms,

The Han Emperor sought a great beauty.

$\mathrm{Xu}$ : The beauty-loving monarch longed year after year

To find a beautiful lady without peer [7].

This example shows how Xu takes a more nuanced consideration about the reader's perception than the other translators. Hanhuang literally refers to Liu Che, an ambitious emperor in the Han Dynasty, but actually refers to Emperor Xuan Zong. In ancient China, it is not allowed to use the name of the emperor. Thus, Ban Juyi used hanhuang insinuating Emperor Xuan Zong and avoided bringing up the emperor's name, since it cannot be presumed that English readers have this knowledge.

Fletcher translates hanhuang into "the Lord of Han". The definition of "lord" is a man who has a high status in the aristocracy. This is especially relevant in Britain and other countries in Europe and "lord" has a different meaning from "emperor" in ancient China. Fletcher's translation loses the real meaning and does not compensate for this. "Majesty" in English is used for addressing the king or queen and therefore can also be considered unsuitable and does not cover the load. Taking into consideration the Yangs, he translates hanhuang into "Han Emperor" without giving any context which may be confusing for the reader. Xu translates hanhuang into "monarch" and adds an annotation: Emperor Xuan Zong (reigned 725-768) of the Tang Dynasty. "Monarch" means a nation's ruler in a hereditary position [7] and is thus also suitable for rulers in Chinese feudal society. Previous analysis shows that Xu gives more consideration to the reader's reception than other translators.

\subsection{Combining Literal Translation with Free Translation}

Free translation is a technique that reproduces the original meanings of the 
source text, without strictly following its form [7]. It can be difficult for target readers to understand figurative meanings of certain cultural images. By taking cultural backgrounds of target readers into account, explicit meanings of original images can be presented by translators.

Original: Fu Rong Zhang Nuan Du Chun Xiao

Fletcher: How warm in her pure curtains

To pass a night of spring!

Giles: Amid the delights of the Hibiscus Pavilion

she passed the soft spring nights.

The Yangs: Behind the warm lotus-flower curtain,

They took their pleasure in the spring night.

$\mathrm{Xu}$ : In lotus-flower curtain she spent the night blessed [7]

Chun Xiao is often used in Chinese literary works and means a wedding night, instead of a night during spring [7], since Chun (spring) holds the meaning of joy and pleasure. Fletcher, Giles and the Yangs translate chunxiao literally to "a night of spring”, "spring nights" and "spring night”. Spring night however does not convey the real connotation and meaning, this might not be understood by the English reader. Xu, on the contrary, translates chunxiao into "blessed night", which more accurately [7] has a deeper meaning and showcases the sincere love between Emperor Xuan Zong and Lady Yang [7].

\section{Discussion}

Taking into consideration different strategies as discussed in this paper, the aim is to understand which techniques could be considered as best practices. As identified by the Penguin classics the best practices are foreignization, scholarly annotation, reader-oriented strategy, and radical alteration of the text to the cognitive understanding of the English reader. Foreignization refers to keeping the Chinese element into the text and using it as a form of originality and stays close to the Chinese cultural element. Even though this technique is praised for originally, this research did not find that foreignization is found to be the technique that is able to convey cultural meaning, since most of the research discusses that the transference of culture is part of optimal translation.

In contrast, scholarly annotation refers to adding explanation of the meaning in order to give certain words and sentences (cultural and political) context. This could even be done by well-known scholars, writers or translators in order to make translated text more legitimate and richer of Chinese meaning. N. K. Mao praises Fortress Besieged in its extended afterword, the novel for its greatness and adds criticisms in order to increase its legitimacy. Moreover, the translator Lin also adds context and his opinion to the translation of $A$ Nun of Taishan which was received as greatly translated work.

As Zheng states the combination of free translation, which is a reader-oriented style, in combination with scholarly annotation can contextualize a text for the English reader. By doing this analysis, it has been observed that the 
scholarly annotation in combination with free translation has received scholarly attention. Research by Zheng and Yang have shown that this technique is a good way to transfer Chinese culture to the understanding of the English reader while keeping the aesthetics and pleasurable reading experience.

Moreover, a technique which has been praised as a good technique for the Penguin Classics and by other translators is the reader-oriented strategy. The reader-oriented strategy really takes into consideration the cognitive understanding of the reader. The translator of The Complete Fiction of Luxun replaced Chinese culture-specific sentences in the novel with simple and colloquial English expressions that aim to cover the load but also create a sense of familiarity for the reader. To add to this, one of the famous translators and academics, Zhang Peiji, produced a translation that is understandable and appreciated by English readers. Zhang Peiji used techniques which are reader oriented. In Zhang Peiji's opinion the loss of some cultural meaning is not a problem when the reader gets a more familiar sense when reading the text. Thus, the trade-off between translating words literally and transferring the cultural meaning so that the reader understands it should be considered.

However, certain limitations within this research can be outlined for future research. For instance, the reception theory could be more applied on the Penguin Classics. The perceptions and opinions of readers could be compared to include their views even more. Moreover, this research has taken poetry as well as literature into consideration while a distinction could be made between those two to get a more detailed understanding of how on the one side literature is received and on the other side poetry is received.

\section{Conclusion}

This research has uniquely contributed to literature by comparing the well-received Penguin Classic techniques with other works of Chinese translators and by this means to see whether these techniques overlap. It can be concluded that they do overlap. The strategies applied in Penguin classics are foreignization, scholarly annotation, and reader-oriented strategies or radically rewriting a text. This research adds to the literature which aims to find solutions of translation problems and seeks to improve the techniques used in translating Chinese texts to English. This analysis has shown techniques which have different outcomes in the translation of a text, therefore this is a choice technique. The translator can be free in his or her decision for translation style and the reception of the text depends on the taste of the reader. However, this research aimed to seek the best practices. This research has outlined that the best practice is a combination of translation style where cultural meanings and culturally loaded words are retained while the reading experience remains aesthetic and pleasing. The strategy identified to adhere to this goal is the reader-oriented strategy where words or clauses are translated into English expressions so that the reader understands the saying. This can be performed in combination with (scholarly) annotation, thus adding 
context so that the reader is informed about the cultural and political context. Another way of adding context is to add a description of a Chinese word or saying in the body of the text. Yet, translation remains a very subtle practice where the choice of technique should fit the word, text, genre or audience and therefore the translator bears great responsibility.

\section{Conflicts of Interest}

The author declares no conflicts of interest regarding the publication of this paper.

\section{References}

[1] Tianzhen, X. (2014) The Translation and Dissemination of Chinese Literature: Problems and Essence. Comparative Literature in China, 1, 4-9.

[2] Hu, R. (2009) Explorations into the Essence of English-Chinese and Chinese-English Translation Based on Relevance Theory. English Language Teaching, 2, 12-15. https://doi.org/10.5539/elt.v2n2p12

[3] Ping, L. (2014) Canonization of Chinese Literature in the English-Speaking World: Construction, Restrictions and Measures. International Journal of English and Literature, 5, 257-265. https://doi.org/10.5897/IJEL2014.0598

[4] Chan, K. and Tam, K. (2012) Culture in Translation. Open University of Hong Kong Press, Kowloon, Hong Kong.

[5] Menghan, Q. (2017) Penguin Classics and the Canonization of Chinese Literature in English Translation. Translation and Literature, 26, 295-316. https://doi.org/10.3366/tal.2017.0302

[6] Zheng, J. (2016) On the English Translation of Chinese Modern Essays from the Perspective of Cognitive Context: A Case Study of Zhang Peiji's English Translation of Chinese Essay "Xiang”. International Journal of Applied Linguistics and English Literature, 5, 96-101. https://doi.org/10.7575/aiac.ijalel.v.5n.5p.96

[7] Yang, Y. (2019) On Translation of Cultural Images in Chang Hen Ge from the Perspective of Reception Theory. Chinese Journal of Applied Linguistics, 42, 527-541. https://doi.org/10.1515/CJAL-2019-0031

[8] Feng, Q.H. (2010) A Practical Course Book on Translation. Shanghai Foreign Language Education Press, Shanghai. 